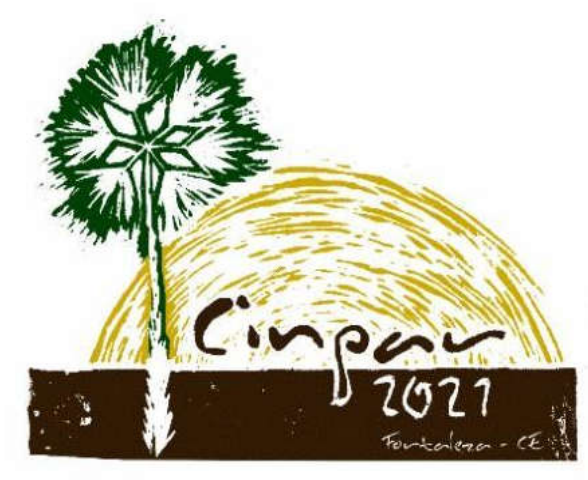

XVII Congresso Internacional sobre Patologia e Reabilitação das Construções

XVII Congreso Internacional sobre Patología y Rehabilitación de las Construcciones

XVII International Conference on Pathology and Constructions Rehabilitation

FORTALEZA (Brasil), 3 a 5 de junho de 2021

https://doi.org/10.4322/CINPAR.2021.162

\title{
Considerações de interesse sobre a avaliação experimental de elementos estruturais em situação de incêndio: resistência ao fogo
}

\section{Considerations of interest about experimental evaluation of structural elements when exposed to fire: fire resistance}

\author{
Camila SIMONETTI ${ }^{1}$, Nicolas Gomes LAURENTINO ${ }^{2}$, Vanessa Oerle KAUTZMANN ${ }^{3}$, Bernardo Fonseca \\ TUTIKIAN $^{4}$ \\ ${ }^{1}$ UFRGS, Porto Alegre/RS, Brasil, cacaks@hotmail.com \\ 2 UNISINOS, São Leopoldo/RS, Brasil, nicolasgl@edu.unisinos.br \\ ${ }^{3}$ UNISINOS, São Leopoldo/RS, Brasil, voerlek@unisinos.br \\ ${ }^{4}$ UNISINOS, São Leopoldo/RS, Brasil, bftutikian@unisinos.br
}

Resumo:

A segurança contra incêndio é um tema em evidência no cenário brasileiro desde as últimas catástrofes nacionais, demonstrando progresso significativo após sinistros ocorridos na década de 1970 . No Brasil, a pesquisa sobre segurança contra incêndio está em constante evolução com o desenvolvimento de regulamentações e de dados científicos relevantes para o âmbito nacional e internacional. Nesse contexto, ensaios experimentais de resistência ao fogo são essenciais para a compreensão do comportamento de estruturas em situação de incêndio. $O$ objetivo desse artigo foi realizar uma pesquisa bibliográfica sobre os principais resultados brasileiros em ensaios experimentais em escala real sobre resistência ao fogo de elementos estruturais. Foi observado que os principais ensaios realizados são em sistemas verticais, com ou sem função estrutural. Em relação aos materiais utilizados, é notório o estudo prioritário em estruturas de concreto, seguido por estruturas em alvenaria e em madeira. Diversas pesquisas experimentais alimentam análises teóricas com simulação, reforçando a importância de ensaios experimentais.

Palavras-chave: Segurança contra incêndio. Resistência ao fogo. Concreto. Ensaio experimental.

\begin{abstract}
:
Fire safety has been a concern in Brazil since its national catastrophes that occurred in the 1970s, demonstrating significant progress and causing research on fire safety to be constantly evolving in this country with the development of regulations and scientific data relevant to the national and international scope. In this context, experimental fire resistance tests are essential for understanding the behavior of structures in a fire situation. The objective of this article was to build a bibliographic research on the main Brazilian results in experimental trials on a full scale. It was observed that the main tests carried out have been on vertical systems with or without structural function. Regarding the materials used, the priority of study has been on concrete structures followed by masonry and wooden structures. Various experimental research feeds theoretical analyses with simulation, reinforcing the importance of experimental tests.
\end{abstract}

Keywords: Fire safety. Fire resistance. Concrete. Experimental analysis. 


\section{Introdução}

A segurança contra incêndio nas edificações é um requisito necessário para preservar a vida dos usuários durante o evento de um incêndio. A ocorrência de incêndios em edificações demonstra uma preocupação real, principalmente com o aumento no número de edificações construídas. Por exemplo, no estado de São Paulo, em registro realizado pelo corpo de bombeiros (CBPMSP, 2021; PEREIRA, 2009), evidencia-se aumento de mais de $100 \%$ no número de ocorrências de incêndio nos últimos 30 anos.

A ocorrência de incêndios de grandes proporções mostra a importância da avaliação experimental de diferentes sistemas construtivos, bem como a mobilização e a atualização da regulamentação brasileira. No Brasil, até a década de 1970, a regulamentação se restringia ao Código de Obra dos municípios, não levando em consideração diversos fatores essenciais, como o dimensionamento das saídas de emergência ou a maior restrição na compartimentação entre sistemas.

A primeira regulamentação sobre segurança contra incêndio surgiu no Brasil, em meados de 1975, após a ocorrência dos incêndios dos edifícios Joelma e Andraus, em São Paulo. Em 1974, no mesmo ano do sinistro no Edifício Joelma, em São Paulo, foi realizado o primeiro simpósio de segurança contra incêndio no Brasil. Logo após este evento, normas como a NBR 9077 - Saídas de Emergência em Edifícios Altos (ABNT, 1974) e Decreto-Lei no 247 (BRASIL, 1975), que dispõe sobre Segurança Contra Incêndio e Pânico do estado do Rio de Janeiro, foram desenvolvidas.

No Rio Grande do Sul, a partir do incêndio na boate Kiss, em 2013, em Santa Maria, o país iniciou um debate sobre desenvolvimento de normas que possam evitar a repetição do ocorrido na cidade gaúcha. Peritos opinam que as mudanças tornaram as regras mais rígidas para obtenção de alvarás para prédios comerciais. Nesse cenário, no dia 31 de março de 2017, foi publicada a Lei no 13.425 (BRASIL, 2017), conhecida como a Lei Kiss.

Acompanhando a regulamentação, tem-se a normalização que, através de normas em constante aprimoramento, estabelece soluções por consenso das partes interessadas. Para a sua formatação, podem ser utilizadas, como base, normas já desenvolvidas internacionalmente. Dentre os laboratórios internacionais que pesquisam segurança contra incêndio, podem ser citados Building Research Establishment, National Institute of Standards and Technology e Blockchain Research Institute. Organizações ativas responsáveis por grande parte do desenvolvimento nesta área são: International Association for Fire Safety Science, National Fire Protection Association e Society of Fire Protection Engineers.

Na década de 1990, o Corpo de Bombeiros da Polícia Militar do Estado de São Paulo outorgou uma instrução técnica exigindo que fossem avaliadas a resistência e a segurança de projetos de estruturas contra incêndios. Como não havia referências sobre o assunto, a Associação Brasileira de Normas Técnicas (ABNT) recebeu a incumbência de criar a primeira normatização nacional para projetos de estruturas metálicas. E, em 2004, estendeu o projeto para as estruturas de concreto.

Como consequência, laboratórios começaram a se especializar em segurança contra incêndio, surgindo, assim, os primeiros ensaios de resistência ao fogo em escala real feitos no Brasil. Inicialmente, o Laboratório de Segurança ao Fogo e a Explosões do Instituto de Pesquisas Tecnológicas do Estado de São Paulo e o Laboratório de Tecnologia do Ambiente Construído das Centrais Elétricas de Furnas, em Aparecida de Goiânia, em Goiás, eram os únicos que possuíam o equipamento necessário para o desenvolvimento dessa área. Posteriormente, seguidos por outros institutos de pesquisa, como o Instituto Tecnológico em Desempenho e Construção Civil, na Universidade do Vale do Rio dos Sinos (UNISINOS), em São Leopoldo, foram responsáveis pela compreensão do comportamento de vários materiais e estruturas em altas temperaturas.

Dessa forma, o objetivo desse artigo foi realizar uma pesquisa bibliográfica sobre os principais resultados brasileiros em ensaios experimentais em escala real, sobre resistência ao fogo de elementos estruturais, angariando pesquisas desenvolvidas nos últimos 20 anos, reunindo assim trabalhos de diferentes instituições e com diferentes sistemas construtivos. 


\section{Ensaio experimental de resistência ao fogo}

A resistência ao fogo aplica-se a elementos estruturais e de compartimentação, e pode ser vista como uma medida da capacidade de desempenhar o papel que lhe foi atribuído, determinado em projeto, apesar da ação de um incêndio (DENOËL, 2007). Após a inflamação generalizada, a temperatura do ambiente é tão elevada que não é possível sobreviver no recinto e os objetivos passam a ser evitar a propagação do incêndio através da compartimentação e preservar a estabilidade estrutural da edificação para permitir o acesso às equipes de combate, cumpridos através da resistência ao fogo dos sistemas construtivos.

Existem diversas normas a nível nacional e internacional que abordam métodos de ensaio para determinação de resistência ao fogo de elementos construtivos e materiais. As principais referências normativas podem ser consultadas através da Associação Brasileira de Normas Técnicas. no Brasil, da International Organization for Standardization e da British Standards Institution, na Europa, e da American Society for Testing and Materials, nos Estados Unidos.

$\mathrm{Na}$ atual regulamentação internacional, a resistência ao fogo é classificada pela resistência estrutural (R), pela integridade (E) e pelo isolamento térmico (I). A resistência estrutural está associada à capacidade portante do sistema construtivo, ou seja, capacidade de resistir mecanicamente sem perder suas propriedades estruturais. A estanqueidade está relacionada com a capacidade do elemento construtivo de impedir a passagem de chamas e de gases quentes para uma área não afetada pelo fogo. Já o isolamento térmico garante que, na face não exposta do elemento, não sejam atingidas temperaturas críticas, sendo relacionado à capacidade do elemento construtivo de impedir o aumento da temperatura na face não exposta diretamente ao fogo.

Estas siglas R, E e I podem ser conjugadas de diversas formas, caracterizando o elemento em análise, sendo seguidas de um número que reflete o tempo em minutos que o material consegue garantir os requisitos: 15 , $30,45,60,90,120,180,240$ e 360 minutos.

\section{Metodologia}

Para a realização deste trabalho, foi realizada uma pesquisa bibliográfica dos principais documentos de âmbito nacional sobre resistência ao fogo com trabalho experimental em escala real, sendo consultados livros, teses e dissertações, artigos em periódicos científicos ou publicados em congressos. Dos documentos pesquisados, foram escolhidos os trabalhos mais significativos realizados nos últimos 20 anos, que servem como representativo de outras pesquisas feitas, para mostrar a evolução dos ensaios de resistência ao fogo no Brasil e as principais contribuições obtidas. Os resultados trazem a análise do material coletado, mostrando uma visão das características gerais das estruturas avaliadas e do tipo de material ensaiado. Vale ressaltar que não foi realizada uma pesquisa experimental acerca do tema.

\section{Avaliação experimental da resistência ao fogo de elementos estruturais}

\subsection{Características gerais}

As principais pesquisas sobre resistência ao fogo com ensaios em escala real, no Brasil, podem ser visualizadas no Quadro 1. São observadas pesquisas em estruturas e/ou elementos de concreto, madeira, alvenaria de vedação e estrutural. Dentre os elementos de concreto armado encontram-se pilares, placas e vigas. 
Quadro 1 - Principais estudos brasileiros experimentais em escala real, em elementos estruturais e em altas temperaturas

\begin{tabular}{|c|c|c|}
\hline Fonte & Objetivo da pesquisa & $\begin{array}{c}\text { Tipo e } \\
\text { instituição }\end{array}$ \\
\hline Pinto (2005) & $\begin{array}{c}\text { Determinação de um modelo de taxa de carbonização transversal a grã } \\
\text { para o Eucalyptus citriodora e } E \text {. grandis utilizando peças de madeira com } \\
\text { pequena dimensão e vigas estruturais }\end{array}$ & $\begin{array}{l}\text { Tese } \\
\text { USP }\end{array}$ \\
\hline Gomide (2008) & $\begin{array}{l}\text { Colunas esbeltas de pequeno diâmetro mistas de aço preenchidas com } \\
\text { concreto em situação de incêndio }\end{array}$ & $\begin{array}{l}\text { Dissertação } \\
\text { UNICAMP }\end{array}$ \\
\hline Sant' Anna (2009) & $\begin{array}{l}\text { Pilares mistos esbeltos em aço preenchidos com concreto, de seção } \\
\text { quadrada, em situação de incêndio }\end{array}$ & $\begin{array}{l}\text { Dissertação } \\
\text { UNICAMP }\end{array}$ \\
\hline Leite Júnior (2009) & $\begin{array}{l}\text { Colunas mistas esbeltas de aço preenchidas com concreto de alta } \\
\text { resistência em temperatura ambiente e em situação de incêndio }\end{array}$ & $\begin{array}{c}\text { Tese } \\
\text { UNICAMP }\end{array}$ \\
\hline Britez (2011) & $\begin{array}{l}\text { Avaliação de pilares de concreto armado colorido de alta resistência } \\
\text { submetidos a elevadas temperaturas }\end{array}$ & $\begin{array}{l}\text { Tese } \\
\text { USP }\end{array}$ \\
\hline Rosemann (2011) & $\begin{array}{l}\text { Resistência ao fogo de paredes de alvenaria estrutural de blocos cerâmicos } \\
\text { pelo critério de isolamento térmico }\end{array}$ & $\begin{array}{l}\text { Dissertação } \\
\text { UFSC }\end{array}$ \\
\hline Rigão (2012) & $\begin{array}{l}\text { Comportamento de pequenas paredes de alvenaria estrutural frente a } \\
\text { altas temperaturas }\end{array}$ & $\begin{array}{l}\text { Dissertação } \\
\text { UFSM }\end{array}$ \\
\hline Schäfer (2015) & $\begin{array}{c}\text { Análise da influência de elevadas temperaturas em revestimento de } \\
\text { argamassa utilizando blocos cerâmicos em mufla e ensaio de paredes de } \\
\text { alvenaria }\end{array}$ & $\begin{array}{l}\text { Dissertação } \\
\text { UNISINOS }\end{array}$ \\
\hline Bolina (2016) & $\begin{array}{l}\text { Avaliação experimental da influência dos requisitos de durabilidade na } \\
\text { segurança contra incêndio de protótipos de pilares pré-fabricados de } \\
\text { concreto armado }\end{array}$ & $\begin{array}{l}\text { Dissertação } \\
\text { UNISINOS }\end{array}$ \\
\hline Moreira (2017) & $\begin{array}{l}\text { Estudo da influência do teor de umidade na resistência ao fogo de placas } \\
\qquad \text { maciças pré-fabricadas de concreto }\end{array}$ & $\begin{array}{l}\text { Dissertação } \\
\text { UNISINOS }\end{array}$ \\
\hline Souza (2017) & $\begin{array}{l}\text { Avaliação da influência da espessura do revestimento argamassado e do } \\
\text { carregamento no comportamento da alvenaria frente a altas temperaturas } \\
\text { com sistemas de vedação estrutural em tamanho real }\end{array}$ & $\begin{array}{l}\text { Dissertação } \\
\text { UNISINOS }\end{array}$ \\
\hline Bueno (2019) & $\begin{array}{l}\text { Avaliação da resistência ao fogo de paredes de alvenaria de blocos } \\
\text { cerâmicos com instalações prediais }\end{array}$ & $\begin{array}{l}\text { Dissertação } \\
\text { UNISINOS }\end{array}$ \\
\hline Simonetti (2020) & $\begin{array}{l}\text { Avaliação do comportamento ao fogo de placas de vedação de concreto } \\
\text { com inserção de resíduos de pneus inservíveis }\end{array}$ & $\begin{array}{l}\text { Tese } \\
\text { UNISINOS }\end{array}$ \\
\hline $\begin{array}{l}\text { Sylverio e Figueiredo } \\
\text { (2020) }\end{array}$ & $\begin{array}{l}\text { Avaliação da resistência ao fogo do concreto para revestimento de túneis } \\
\text { utilizando ensaio de resistência ao fogo }\end{array}$ & $\begin{array}{c}\text { Artigo } \\
\text { USP }\end{array}$ \\
\hline
\end{tabular}

A maior parte das pesquisas encontradas utiliza um forno vertical normatizado para a avaliação experimental, que é comum para avaliação de pilares, placas e paredes divisórias com e sem função estrutural. $O$ ensaio de lajes ou de outros elementos horizontais exige equipamento de resistência ao fogo específico, em geral, forno horizontal, que atenda aos critérios normativos. No Brasil, é possível encontrar fornos para elementos horizontais em escala real na Escola de Engenharia de São Carlos, Universidade de São Paulo, e recentemente no itt Performance, na UNISINOS.

\subsection{Resultados de avaliação experimental da resistência ao fogo de elementos estruturais}

A pesquisa apresentada no Quadro 1 mostra que o maior número de ensaios é voltado para estruturas de concreto devido a esse material ser o mais empregado na construção civil brasileira.

O concreto é reconhecido pela sua boa resistência em temperaturas elevadas em virtude de suas características térmicas, tais como a incombustibilidade e a baixa condutividade térmica. Além disso, o concreto não exala gases tóxicos ao ser aquecido (MEHTA; MONTEIRO, 2014). No entanto, a classificação dos sistemas construtivos frente à resistência ao fogo através de ensaios experimentais é mais assertiva que métodos tabulares ou simulações computacionais. 
Outro fator relevante para o estudo experimental deste material é o seu comportamento em elevadas temperaturas, que pode apresentar desplacamento e degradação em diferentes níveis. Como fenômenos de degradação frente a altas temperaturas dependem de uma série de fatores, torna-se mais fidedigno entender o processo em escala real e de forma experimental.

Quando outros materiais são agregados ao concreto, a combustíveis ou a outros com características desconhecidas, obtém-se um novo produto que deve ser avaliado quanto ao seu desempenho ao fogo (ONO, 2007). Simonetti (2020) avaliou o comportamento ao fogo de placas de vedação de concreto, elaboradas com material reaproveitado de pneus inservíveis, utilizando fibras metálicas recicladas e agregados reciclados de borracha de pneu inservível. O concreto com maior teor de adição de borracha, frente à resistência ao fogo, apresentou sinais de desplacamento explosivo, reforçando o alerta realizado por Ono (2007) quanto à necessidade de avaliação de novos compósitos que alteram a composição ou as propriedades originais do concreto.

Ao estudar a influência do teor de umidade na resistência ao fogo de placas maciças pré-fabricadas de concreto, Moreira (2017) observou que os menores teores de umidade estavam presentes em amostras com idades de cura mais elevadas, apresentando melhor desempenho quando submetidas a altas temperaturas. Costa e Britez (2011) destacam que os experimentos envolvendo concreto submetido a elevadas temperaturas deveriam ser realizados em amostras com pelo menos um ano de idade, para que o teor de umidade, a maturidade e o grau de hidratação sejam mais compatíveis com as edificações de concreto existentes e em pleno uso, sujeitas à ocorrência de incêndio.

Britez (2011) realizou a avaliação de pilares de concreto armado, colorido e de alta resistência, submetidos a elevadas temperaturas, sendo um programa experimental pioneiro. Quanto aos resultados obtidos no ensaio principal de simulação de incêndio, destaca-se que o pilar protótipo de concreto colorido armado de alta resistência teve um bom desempenho, comportando-se de forma íntegra e que o emprego de óxido de ferro $\left(\mathrm{Fe}_{2} \mathrm{O}_{3}\right)$, principal originalidade da pesquisa, pode atuar também como um excelente termômetro natural, auxiliando na avaliação da estrutura pós-incêndio através de indicadores colorimétricos.

Ainda sobre o concreto de alta resistência, Leite Júnior (2009) investigou o efeito do fogo em colunas esbeltas de aço com e sem preenchimento em concreto de alta resistência, submetidas a diferentes níveis de carga. Ao final da pesquisa, o autor constatou que o preenchimento das colunas esbeltas de aço com concreto de alta resistência propiciou melhorias significativas no tempo de resistência ao fogo dessas colunas.

Complementando o estudo em pilares de concreto, Bolina (2016) avaliou experimentalmente a influência dos requisitos de durabilidade na segurança contra incêndio de protótipos de pilares pré-fabricados de concreto armado. $\mathrm{O}$ autor observou que os parâmetros de durabilidade do concreto influenciaram no grau de desplacamento, havendo preponderância do diâmetro das barras e da espessura de cobrimento no tempo de resistência ao fogo dos pilares.

Quanto à resistência ao fogo do concreto para revestimento de túneis, Sylverio e Figueiredo (2020) explicam que o lascamento explosivo pode ser apontado como uma condição crítica em relação aos outros efeitos de deterioração. Isso porque a sua ocorrência diminui a espessura resistente da estrutura e elimina a ação de proteção das camadas superficiais em relação ao restante do revestimento.

Em comparação com o concreto, foi possível notar que o estudo em escala real de elementos de madeira em situação de incêndio é mais escasso, talvez por não ser um método construtivo amplamente utilizado no Brasil como em outros países, como o wood frame nos Estados Unidos. O Núcleo de Referência em Tecnologia da Madeira e o WoodRise - Congresso Mundial de Construção Civil em Madeira - colocam em pauta a construção de prédios de madeira.

Em relação às estruturas de madeira, Pinto (2005) considera a taxa na qual a madeira se converte em carvão determinante para a avaliação da resistência ao fogo, pois o colapso de elementos estruturais de madeira e de seus derivados, quando expostos ao fogo, ocorre principalmente pela redução da área resistente da seção, devido à carbonização. A autora explica que a resistência ao fogo de estruturas de madeira depende, portanto, das dimensões da seção transversal que são reduzidas gradualmente ao ser exposta ao fogo. Uma sugestão da autoria é o investimento em pesquisas para a caracterização e a determinação da taxa de carbonização das espécies de madeira brasileira. 
Paredes de alvenaria em geral apresentam boa estanqueidade, não sendo observada a passagem de gases aquecidos, podendo ser empregadas onde um alto nível de resistência ao fogo seja exigido. Rosemann (2011) adiciona que paredes com revestimento de argamassa apresentam resistência ao fogo em tempo superior às amostras sem a aplicação de revestimentos, podendo chegar a um aumento de até $80 \%$ no tempo de resistência ao fogo. Souza (2017) e Schafer (2015) complementam que a espessura do revestimento em argamassa interfere no comportamento ao fogo de paredes de alvenaria, incidindo em melhora nas propriedades de isolamento térmico das paredes. Rigão (2012) ressalta que o tipo de agregado usado nas argamassas de revestimento influencia na perda de massa e na estabilidade do material quando submetidas a altas temperaturas.

Rosemann (2011) indica que o preenchimento com areia dos alvéolos dos blocos pode dobrar o tempo de resistência ao fogo de paredes de alvenaria, quando comparadas a paredes sem o preenchimento, sendo uma alternativa interessante do ponto de vista técnico e econômico. Bueno (2019) aponta que, nas regiões com aberturas de instalações prediais que permitem a passagem de gases quentes, a superfície não exposta às altas temperaturas perde sua capacidade de isolamento em um menor tempo em comparação à superfície no entorno, o que reduz a resistência ao fogo de sistemas de compartimentação.

Além dos trabalhos descritos no Quadro 1, com foco em estruturas, observa-se o desenvolvimento de pesquisas em outros segmentos da segurança contra incêndio. Como exemplo, o estudo de Oliveira (2007) buscou avaliar a resistência ao fogo de diferentes tipos de tubulações com compostos vinílicos, usadas em sistemas de chuveiros automáticos, concluindo que o maior teor de cloro na composição aumenta a resistência ao fogo das tubulações.

\section{Conclusões}

As principais considerações sobre a avaliação experimental de elementos estruturais em situação de incêndio, frente à resistência ao fogo, considerando as pesquisas apresentadas ao longo da seção 4, podem ser pontuadas em:

- Em relação aos materiais, as adições ou substituições no concreto, assim como os agregados em argamassas, trazem mudanças na composição dos materiais utilizados que podem causar variações no seu comportamento em situação de incêndio, refletindo no sistema construtivo utilizado;

- A predominância de estudos sobre elementos de concreto em comparação aos demais, como elementos metálicos ou em madeira, mostra a relevância desse material para a construção civil brasileira no atual cenário;

- A avaliação experimental de elementos estruturais em situação de incêndio, sob carga, e em escala real, implica a aquisição de equipamentos de grandes dimensões e de custo elevado, sendo a sua operação e funcionamento complexos. Tendo em vista essas dificuldades, são poucos os núcleos de pesquisa brasileiros com tal capacidade.

É necessário enfatizar a importância do estudo do comportamento de elementos estruturais exposto a altas temperaturas, buscando preencher as lacunas técnicas e científicas acerca dessa temática. A contribuição para a segurança contra incêndio vai além da proteção patrimonial quando se entende a seriedade dos danos ocorridos num sinistro, buscando a preservação da vida dos usuários e das equipes de resgate.

\section{Referências Bibliográficas}

ASSOCIAÇÃO BRASILEIRA DE NORMAS TÉCNICAS. NBR 9077: Saídas de emergência em edifícios altos Procedimento. Rio de Janeiro, 1974.

BOLINA, F. L. Avaliação experimental da influência dos requisitos de durabilidade na segurança contra incêndio de protótipos de pilares pré-fabricados de concreto armado. 2016. 171 f. Dissertação (Mestrado) - Universidade do Vale do Rio dos Sinos, Programa de Pós-Graduação em Engenharia Civil. São Leopoldo, RS, Brasil, 2016. 
BRASIL. Decreto-lei n 247, de 21 de julho de 1975. Diário Oficial da República Federativa do Brasil, Brasília, DF, 1975.

BRASIL. Lei $\mathbf{n}^{\circ}$ 13.425, de 30 de março de 2017. Diário Oficial da República Federativa do Brasil, Brasília, DF, 31 de março de 2017.

BRITEZ, C. A. Avaliação de pilares de concreto armado colorido de alta resistência, submetidos a elevadas temperaturas. 2011. 252 f. Tese (Doutorado) - Universidade de São Paulo, Escola Politécnica. São Paulo, SP, Brasil, 2011.

BUENO, G. M. Avaliação da resistência ao fogo de paredes de alvenaria de blocos cerâmicos com instalações prediais. 2019. 185 f. Dissertação (Mestrado) - Universidade do Vale do Rio dos Sinos, Programa de Pós-Graduação em Engenharia Civil. São Leopoldo, RS, Brasil, 2019.

CORPO DE BOMBEIROS DA POLÍCIA MILITAR DO ESTADO DE SÃO PAULO. Dados Estatísticos do Corpo de Bombeiros do Estado de São Paulo. Disponível em: <http://www.ssp.sp.gov.br/estatistica/corpobombeiro.aspx>. Acesso em: 4 mar. 2021.

COSTA, C. N.; BRITEZ, C. A. Ações do fogo nas estruturas de concreto. In: ISAIA, G. C. (ed.). Concreto: ciência e tecnologia. 1. ed. São Paulo, SP: Instituto Brasileiro do Concreto, 2011. p. 1029-1068.

DENOËL, J. Fire safety and concrete structures. Brussels: Federation of Belgian Cement Industry, 2007.

GOMIDE, K. A. Colunas esbeltas de pequeno diâmetro mistas de aço preenchidas com concreto em situação de incendio. 2008. 246 f. Dissertação (Mestrado) - Universidade Estadual de Campinas, Faculdade de Engenharia Civil, Arquitetura e Urbanismo. Campinas, SP, Brasil, 2008.

LEITE JÚNIOR, G. S. Colunas mistas esbeltas de aço preenchidas com concreto de alta resistência em temperatura ambiente e em situação de incêndio. 2009. 261 f. Tese (Doutorado) - Universidade Estadual de Campinas, Faculdade de Engenharia Civil, Arquitetura e Urbanismo. Campinas, SP, Brasil, 2009.

MEHTA, P. K.; MONTEIRO, P. J. M. Concreto - microestrutura, propriedades e materiais. 3. ed. São Paulo: IBRACON, 2014.

MOREIRA, M. A. B. Estudo da influência do teor de umidade na resistência ao fogo de placas maciças préfabricadas de concreto. 2017. 125 f. Dissertação (Mestrado) - Universidade do Vale do Rio dos Sinos, Programa de Pós-Graduação em Engenharia Civil. São Leopoldo, RS, Brasil, 2017.

OLIVEIRA, C. R. M. DE. Avaliação da resistência ao fogo de tubulações de compostos vinílicos empregadas em sistemas prediais de chuveiros automáticos para extinção de incêndio. 2007. 181 f. Dissertação (Mestrado) - Universidade de São Paulo. São Paulo, SP, Brasil, 2007.

ONO, R. Parâmetros para garantia da qualidade do projeto de segurança contra incêndio em edifícios altos. Ambiente Construído, v. 7, n. jan./mar., p. 97-113, 2007.

PEREIRA, Á. G. Segurança contra incêndios. Engenharia: Construção Civil, n. 596, p. 108-115, 2009.

PINTO, E. M. Determinação de um modelo para a taxa de carbonização transversal a grã para a madeira de E. citriodora e E. grandis. 2005. 138 f. Tese (Doutorado) - Universidade de São Paulo, Escola de Engenharia de São Carlos. São Carlos, SP, Brasil, 2005.

RIGÃO, A. O. Comportamento de pequenas paredes de alvenaria estrutural frente a altas temperaturas. 2012. 142 f. Dissertação (Mestrado) - Universidade Federal de Santa Maria, Programa de Pós-Graduação em Engenharia Civil. Santa Maria, RS, Brasil, 2012.

ROSEMANN, F. Resistência ao fogo de paredes de alvenaria estrutural de blocos cerâmicos pelo critério de isolamento térmico. 2003. 126 f. Dissertação (Mestrado) - Universidade Federal de Santa Catarina, Centro Tecnologico, Programa de Pós-graduação em Engenharia Civil. Florianópolis, SC, Brasil, 2011.

SANT' ANNA, M. S. Pilares mistos esbeltos em aço preenchidos com concreto, de seção quadrada, em situação de incendio. 2009. 178 f. Dissertação (Mestrado) - Universidade Estadual de Campinas, Faculdade de Engenharia Civil, Arquitetura e Urbanismo. Campinas, SP, Brasil, 2009.

SCHÄFER, M. Análise da influência de elevadas temperaturas em revestimento de argamassa. 2015. $137 \mathrm{f}$. Dissertação (Mestrado) - Universidade do Vale do Rio dos Sinos, Programa de Pós-Graduação em Engenharia Civil. São Leopoldo, RS, Brasil, 2015. 
SIMONETTI, C. Avaliação do comportamento ao fogo de placas de vedação de concreto com inserção de resíduos de pneus inservíveis. 2020. 305 f. Tese (Doutorado) - Universidade do Vale do Rio dos Sinos, Programa de Pós-Graduação em Engenharia Civil. São Leopoldo, RS, Brasil, 2020.

SOUZA, R. P. DE. Avaliação da influência da espessura do revestimento argamassado e do carregamento no comportamento da alvenaria frente a altas temperaturas. 2017. 137 f. Dissertação (Mestrado) Universidade do Vale do Rio dos Sinos, Programa de Pós-Graduação em Engenharia Civil. São Leopoldo, RS, Brasil, 2017.

SYLVERIO, M. V. M.; FIGUEIREDO, A. D. DE. Avaliação da resistência ao fogo do concreto para revestimento de túneis. Concreto \& Construções, v. JAN-MAR, n. 97, p. 48-53, 2020. 